\title{
Environmental resources on the Internet
}

By Robert L. Battenfeld and B. Kenton Temple

\section{Stop at the EcoMall and these other information-rich sites}

$\mathbf{T}$ he Internet, originally created as a tool for the military-industrial complex, ${ }^{1}$ has been enthusiastically embraced by the environmental movement as a grassroots communication and information distribution medium. Many environmentalists, as well as the scientific and governmental environmental communities, have established an impressive presence on the Internet. Indeed, the "Net" has become a powerful tool in order to facilitate the analysis, sharing, and distribution of information regarding both local and global environmental issues.

The following listings represent the Internet sites that we found to be most useful and interesting. The very nature of this rapidly evolving global network makes it futile to try to provide a comprehensive list. We hope this article does, however, serve as a starting point for those who wish to use the Internet for environmental research.

\section{General resources}

\section{Environmental directories}

In addition to the general directory services such as Yahoo (http://www.yahoo.com/Society_ and_Culture/Environment_and_Nature/) and Galaxy (http://www.einet.net/galaxy/Community/Environment.html), which both provide pertinent subject areas, there are several good specialized directories for finding environmental information.

- The Best Environmental Resources Directory. This site, maintained by Bruno Kestemont of the Centre for Economic and So- cial Studies on the Environment (CEES) at the Universite Libre de Bruxelles, is an extensive list of other environmental directories and Internet sites arranged in subject order. Access http://www.ulb.ac.he/ceese/cds.html.

- CIESIN (Consortium for International Earth Science Information Network). This "information cooperative" provides topical guides to Internet resources as well as a "kiosk" for sharing unpublished scholarly papers and working papers, software applications, and access to the CIESIN Gateway. The Gateway (http://wwwgateway.ciesin.org/) searches distributed environmental databases worldwide Access: http://www.ciesin.org/IC/info-home. html.

- EcoWeb-EcoGopher-EcoLynx. This directory from the University of Virginia includes links to subject groupings and alphabetical lists of resources. The site includes archives of environmental mailing lists and is keyword searchable. Access: http://ecosys.drdr.virginia.edu/ EcoWeb.html, gopher://ecosys.drdr.virginia. edu, telnet://ecosys.drdr.virginia.edu, login as "lynx".

- Envirolink. Claiming to be the largest online environmental resource on the planet, this visually appealing site provides access to projects that include a "library" of links by subject; green marketplace services; a list of online publications; an art gallery; connections to a forum; a freenet site; and an environmental newswire service. Also includes an archive of mailing lists and EnviroChat, an online conference service. Access: http://www.envirolink.org/

\section{Otber directories}

- Argus Clearinghouse-Environment. Formerly known as the Clearinghouse for Sub- 


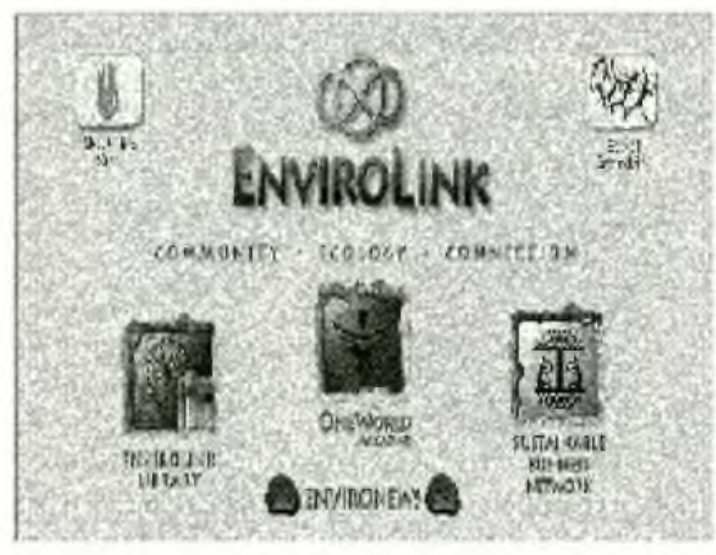

ject-Oriented Internet Resource Guides, this site provides access to evaluative hypertext guides on specific topics. The section on the environment is fairly extensive and most guides are updated within the last twelve months. Access: http://www.clearinghouse.net/tree/ envir.html.

- EcoNet. From the Institute for Global Communication, this searchable directory of environmental issues includes information found on EcoNet and on the Internet. Also includes news items and press releases. Access: http:// www.igc.org/igc/econet/.

- Greennet. This United Kingdom-based site has a European and developing country emphasis on the environment, peace, and human rights providing links to resources in Asia, Europe, Africa, and the Pacific Rim. Access: http://www.gn.apc.org/

- E-Tip. A cooperative project of American and Russian environmental and technology specialists, this site provicles an annotated guide to technical environmental information on the Net. It is composed of Internet databases with guicles for each, as well as other information sources. Access: http://ecologia. nier.org/.

\section{Online publications}

- Greenotes. This is the newsletter of ALA's Social Responsibilities Round Table Task Force on the Environment. This premiere issue includes notes about EPA, ALA, and NIE as well as links to notes on education, collection development, research, and the Internet. This is a good place to check new sites and discussion groups and the latest in what is happening at ALA in connection with environmental issues. Access: http://www.ala.org/alaorg/rtables/srrt/ greenotes/greenotes.html.
- Electronic Green Journal. This is an academically sponsored and professionally refereed journal that provides information concerning sources on international environmental topics. It includes articles, bibliographies, reviews, and announcements for the educated generalist and specialists. Access: http://drseuss.lib.uidaho.edu:70/docs/ egj.html.

- eNet Digest. Weekly reviews of international environmental, agricultural, and natural resource sites are provided by this free electronic newsletter. Current issues are delivered to subscribers by electronic mail. Most back issues are archived and available online. Access: http:/ www enetdigest.com/

- E Magazine. This net version of EMagazine gives coverage of key environmental issues and trends, news, individual and consumer product updates, food and environmental health issues, lifestyle tips, commentary, and book and film reviews. The site provides an archive and additional links. Bimonthly. Access: http:/www. emagazine.com/.

\section{News resources}

- CNN-Earth. This site, the environmental section of the popular CNN Interactive Web page, provides full-text news items concerning current environmental issues complete with images, audio, and video clips. Access: http:/ www.cnn.com/EARTH/index.html.

- Eartb Times. This publication is a nonpartisan newspaper on international environmental issues and sustainable development. Also available in a weekly print format, this Internet edition is published daily by journalists associated with the New York Times, Newsweek, NBC News, and others. Current and back issues of this edition can be searched online. Access: http://www.earthtimes.org/ index.html.

\section{Mailing lists and USENET}

For an evaluative list of discussion groups on ecology and environmental studies including mailing lists, newsgroups, and chat, try Diane K. Kovacs's Directory of Scbolarly and Professional E-Conferences available at: http:// www.n2h2.com/KOVACS/S0017s.html or gopher://gopher.usask.ca/1/Computing/Internet Information/Directory of Scholarly Electronic Conferences/.

USENET newsgroups can be accessed using a news reader program such as those avail- 
able through Web browsers such as Netscape Navigator or Internet Explorer. Some of the newsgroups dealing with environmental issues are: alt.energy.renewable, alt.save.the.earth, alt.sustainable.agriculture, sci.bio.conservation, sci.environment, and talk.environment.

\section{Business and economics}

There are several Internet sites devoted to providing economic analysis of environmental pollution and control or for locating "green" companies and products. Also, many individual corporations provide information on their Web sites concerning their environmental policies, such as Exxon (http://www.exxon.com/environment/environment.html) and Amoco (http:

/www.amoco.com/what_we_do/ehs95/ ehsr_1995_toc.htm).

- EPA-Economy and the Environment. This site is maintained by the Office of Policy, Planning, and Evaluation within the U.S. Environmental Protection Agency's extensive Web offerings and contains reports relating to the economic costs and benefits of environmental regulation and controls. Reports can be downloaded in Adobe Acrobat (.pdf) format. Access: http://www.epa.gov/docs/oppe/eaed/ eedhmpg.htm.

- Trade Environmental Database (TED). This database, maintained by the School of International Service at American University, provides cases on issues relating to trade and the environment. Cases are organized into categories such as identification, legal, geographic, trade, environmental, and other factors such as culture and human rights. The North American collection includes information on trade issues such as African bees, NAFTA, shark fisheries, and even space garbage. A well-organized and easy-to-use database that also has search and sort capabilities. Access: http://gurukul.ucc. american.edu/ted/TED.htm

- EcoMall. On this consumer-oriented Web site for locating environmentally responsible "green" companies and products, categories include renewable energy, eco-investments, activism, eco-restaurants, companies and products, business to business, and communications. Access: http://www.ecomall.com/

\section{Environmental ethics}

- Center for Environmental Philosophy. This site is the homepage for the Center for Environmental Philosophy, the International Society for Environmental Ethics, and the envi- ronmental ethics graduate program at the University of North Texas. It includes links to related graduate programs; associations; publications; Enviroethics, an Internet discussion group; and for the print publication Environmental Ethics, providing subscription information, a table of contents for each issue, and a cumulative index. Access: http://www.cep.unt.edu/.

\section{International environmentalism}

- United Nations Environment Programme. Information about the program itself and identification of international environmental issues and challenges can be found at this site. Products and services include the library catalog; publication lists; and a meta-data (data about the content and location of data and holdings) directory that can be searched both geographically and thematically. Access: http:/ www.unep.org/.

- The G7 Group of Nations Environment and Natural Resources Management (ENRM) Project. The G7 Group of Nations is comprised of the major industrial democracies. The project is intended to make global information relating to the state of the earth and its ecosystems fully available. The site includes a useful prototype server of a global virtual distribution library of ENRM data and resources which provides full text, and is keyword searchable. Links to topic working groups, discussion lists, related activities, and meetings are included. A great deal of international environmental information is available here. Access: http://enrm.ceo.org/.

\section{Environmental organizations}

The sheer number of organizations on the Internet prevents us from listing them all. Environmental groups represented on the Internet have such diverse philosophical backgrounds as the Sierra Club (http://www.sierraclub.org), Greenpeace International (http://www. greenpeace.org), and the "Wise Use" movement's Center for the Defense of Free Enterprise (http://www.cdfe.org). The Amazing Environmental Organization WebDirectory (http://www.webdirectory.com), as well as several directories listed above, can be used to find environmental organizations of all descriptions.

\section{Politics and law}

- Campus Green Vote. This well-designed Web site is geared toward college students and 
endeavors to involve students in the political process in order to facilitate environmental protection on the college campus and in the world at large. Access: http://www.cgv.org/ cgv/

- League of Conservation Voters. The League is the bipartisan political arm of the environmental movement. This site contains the "National Environmental Scorecard," containing the environmental voting records of state and federal legislators, and a listing of the so- called "dirty dozen," the members of Congress considered to have the worst environmental voting records. Access: http:// www.lcv.org/

- Indiana University School of LawEnvironmental Law. This site lists Internet resources for law in general and specialized areas. There is a listing for environmental law sites on the Internet as well as a few full-text resources such as the "Endangered Species Act." Access: http://www.law indiana.edu/law/v-lib/ envlaw.html.

\section{Research institutes}

- Biosphere 2. This "artificial environment" that once housed 15 "biospherians" in Oracle, Arizona, has had a controversial history. It now is being managed by Columbia University with the hope that it will yield important information concerning the Earth and its complex natural systems. Visitors can take a "cybertour" and view data and images from the various biomes, including the desert, marsh, ocean, rainforest, and savanna. Access: http:// www.bio2.edu/

- National Institute for the Environment. This institute was created by the Sound Science for the Environment Act (H.R. 2827) in order to improve the scientific decision-making process. This site includes the National Library for the Environment that contains searchable Congressional Service Research Reports and a proposed Encyclopedia of the Environment. Access: http://www.cnie.org/index.shtml.

\section{Federal government and related sites}

Not surprisingly, the federal government has created sites that can fit into all of the categories we have listed. Specific departments, offices, and agencies, especially the EPA and DOE, can be found by browsing the main homepages listed below.

- U.S. Environmental Protection Agency (http://www.epa.gov/).

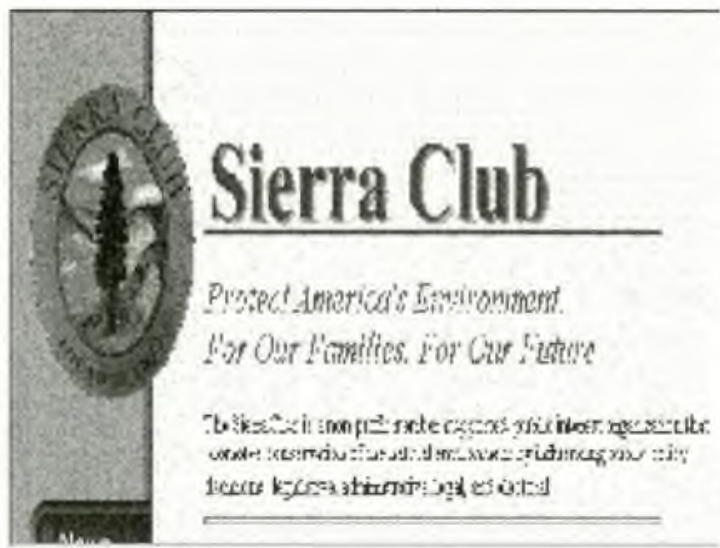

- U.S. Department of Energy (http:/ www.doe.gov/).

- U.S. Nuclear Regulatory Commission (http://www.nrc.gov/).

- U.S. Department of the Interior (http: //www.doi.gov/).

- U.S. Geological Survey, Water Resources Information (http://h2o.er.usgs.gov/).

- U.S. Department of Agriculture, Natural Resources Conservation Service (http: //www.ncg.nrcs.usda.gov/).

- U.S. Department of Commerce, National Oceanic and Atmospheric Administration, Information Services (http://www. esdim.noaa.gov/).

- Environmental Professional's Homepage. Created by John N. Clay and sponsored by GZA GeoEnvironmental Technologies, Inc., this site is more than a comprehensive listing of federal agencies involved with environmental issues. It was created to provide a direct link to primary source, environmen-related information. It is specialized to highlight government regulations, agencies, and health and safety issues and is intended to be useful for environmental professionals. Look here for the full scope of government sites as well as for all environmental issues. Access: http://www. clay.net/govag.html.

\section{Specific environmental issues}

Air and water resources

- Universities Water Information Network. Founded by USGS and housed at Southern Illinois University at Carbondale, the network disseminates information to the water resources community. The site includes links to water experts, organizations, events, and a publication list. Access by keyword is available from here to USGS's Water Resources Scientific 
Information Center to identify abstracts on water research from 1967 to October 1993. A publication list of the Water Resources Research Institute from 1984-1995 is also included. $A c$ cess: http://www.uwin.siu.edu/.

- National Center for Atmospheric Research. This is the homepage for the research center operated in Boulder, Colorado, and funded by the National Science Foundation that conducts research programs with the university community and facilitates technology transfer programs. A large collection of atmospheric and oceanographic data for use in climate research from a variety of databases is accessible from here. Access: http://www.ncar. ucar.edu/

- Water Online. This site is intended as a business connection for the water and wastewater industries. Access: http://www.water online.com/.

\section{Energy}

- Critical Mass Energy Project. Maintained by the advocacy group Public Citizen, this site provides information on nuclear power safety, energy proficiency, renewable energy, radioactive waste, fuel economy, and congressional votes on energy legislation. Access: http: //WwW.citizen.org/public_citizen/CMEP/ home.html.

- CREST (Center for Renewable Energy and Sustainable Technology). Also known as "Solstice," this homepage provides information on energy efficiency, renewable energy, and sustainable technology. Topics include: appliances, lighting, bioenergy, geothermal, solar, and general environmental issues. This site is also the host for the "Maine Solar House," which provides monthly updates on energy use and costs for an actual solar house. Access: http: //solstice.crest.org/.

- Nuclear Energy Institute. This Web site is maintained by the Washington, D.C.-based nuclear industry policy group and includes basic information on nuclear power, safety issues, benefits of nuclear power, and press releases. Access: http://www.nei.org/.

- World Energy Efficiency Association (WEEA). WEEA was founded in 1993 as a nonprofit organization to assist developing countries in accessing and collecting information on energy efficiency. Online resources include the International Directory of Energy Efficient Institutions, case studies, and manuals. Access: http://www.weea.org/.

\section{Population}

- United Nations Population Reference

Bureau. The United Nations Population Information Network (POPIN) provides a network of world population centers to consolidate demographic information including sites such as Princeton University's Population Index (http: //popindex.princeton.edu/). Reports from the International Conference on Population held in Cairo are also available. Access: http://www. undp.org/popin/popin.htm.

- Zero Population Growth (ZPG). This is a population site with an emphasis on the detrimental environmental effects of overpopulation and wasteful consumption. ZPG provides a congressional report card, $\mathrm{K}-12$ curriculum materials, news releases, and excerpts from its periodical ZPG Reporter. Access: http://www. zpg.org/zpg/.

\section{Waste disposal}

- Compost Resource Page. Information and links for home as well as large-scale composting are provided at this site created by Chris Palmarini. Poetry and a quiz game, links to international sites, updates on laws and regulations, newsgroups, and children's activities are included. This site is a must see for any composter. Access: http://www.oldgrowth.org/ compost/.

- Global Recycling Network. The Net's recycling business center, this site has information on news headlines, company directories, equipment, prices on traded recyclables, and educational services. The Reference Library link provides information on sources of grant and capital funding, laws and regulations, resources, and publications. Access: http://grn.com/grn/

- Yale Working Papers on Solid Waste Policy. The full text of strategically commissioned papers from experts on topics that have been neglected in the discussion about solid waste policy are available at this site. Access: http://www.yale.edu/pswp/.

Autbor note: Both the authors maintain environmental resources Web pages that can be located at: http://www.southampton.liunet.edu/ library/environ.htm and http://aztec.lib.utk.edu/ -temple/envirnpg.htm.

\section{Note}

1. Edwin Diamond and Stephen Bates, "The Ancient History of the Internet," American Heritage 46 (October 1995): 34-45. 


\section{Save rime.Speed Research. ASC CDROM als on C}

A powerful, convenient Windows ${ }^{\text {TM }}$ based subscription, ASCE Journals on CD ROM allows you to rapidly and accurately search ASCE journals for all the information pertinent to your civil engineering research needs. And with ASCE Journals on CD ROM, you choose what you want to subscribe to.

Search all the journals you choose to subscribe to, or just one

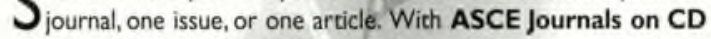
ROM, choose what journals or practice periodicals you need and receive the same top information and research as in the print issues. Our CD ROM subscriptions provides the same material as the print subscriptions. And with ASCE Journals on CD ROM, all the subscriptions you choose are provided on one small, compact, spacesaving disc. Each quarterly disc is a year-to-date cumulation of issues, ending with the entire subscription year. So, no matter when you subscribe during the year, you never miss an issue.
WHAT DO 1334 PAPERS, 1273 AUTHORS, 462 DISCUSSIONS/CLOSURES, AND 25 TOP CIVIL ENGINEERING JOURNALS HAVE IN COMMON?

\section{ONE SMALL DISC.}

\section{Dynamic Versatility...Comprehensive Searches...Easy-to-Use}

\begin{tabular}{|c|c|c|}
\hline $\begin{array}{l}\text { - SGML coded } \\
\text { - Full contents, }\end{array}$ & $\begin{array}{l}\text { - Execute precise } \\
\text { word searches with }\end{array}$ & \multirow{3}{*}{$\begin{array}{l}\text { flexible search engine, an easy-to-use interface, } \\
\text { and quick access navigation tools. Few titles } \\
\text { designed for the Windows environment permit } \\
\text { changing the font size or the type face. This } \\
\text { one does-a welcome feature for aging eyes. } \\
\text { Readers can also zoom the images } \\
\text { from } 50 \% \text { to } 200 \% \text { magnification. }\end{array}$} \\
\hline $\begin{array}{l}\text { - Review an article } \\
\text { outline to quickly } \\
\text { select key sections }\end{array}$ & $\begin{array}{l}\text { Enjange charts } \\
\text { and tables to } \\
\text { yiew in detail }\end{array}$ & \\
\hline $\begin{array}{l}\text { - Use the special book } \\
\text { mark feature to tag } \\
\text { important articles, } \\
\text { sections of text, }\end{array}$ & $\begin{array}{l}\text { Browse an alphabet- } \\
\text { ical index of all } \\
\text { words and terms } \\
\text { used within all issues }\end{array}$ & \\
\hline or illustra & & Against the Grain \\
\hline
\end{tabular}

1997 ASCE Journals and Practice Periodicals: Aerospace Engineering - Architectural Engineering - Bridge Engineering - Cold Regions Engineering - Computing in Clvil Engineering - Construction Engineering and Management - Energy Engineering - Engineering Mechanics - Environmental Engineering - Geotechnical and Geoenvironmental Engineering - Hydraulic Engineering - Hydrologic Engineering - Infrastructure Systems * Irrigation and Drainage Engineering - Management in Engineering - Materials in Civil Engineering - Peformance of Constructed Facilities - Professional Issues in Engineering Education and Practice - Structural Engineering * Surveying Engineering. Transportation Engineering - Urban Planning and Development - Water Resources Planning and Management - Waterway, Port, Coastal, and Ocean Engineering - Practice Periodical on Structural Design and Construction

New in 1997: Journal of Composites for Construction - Practice Periodical of Hazardous, Toxic, and Radioactive Waste Management

ASCE Journals on CD ROM were developed by Reed Technology and Information Services, Inc. with advanced OPTI-Ware software technology.

For a Demonstration Disc, Information or Pricing, contact ASCE:

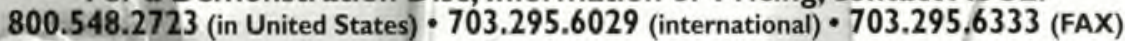

\section{AMERICAN SOCIETY OF CIVIL ENGINEERS}

International Headquarters, 1801 Alexander Bell Dr., Reston, VA 20190-4400; email: marketing@asce,org ·Access ASCE on the World Wide Web www.asce.org 


\section{SOME SCIENTIFIC ACHIEVEMENTS SPEAK VOLUMES} 4<smiles>[123IH]</smiles>

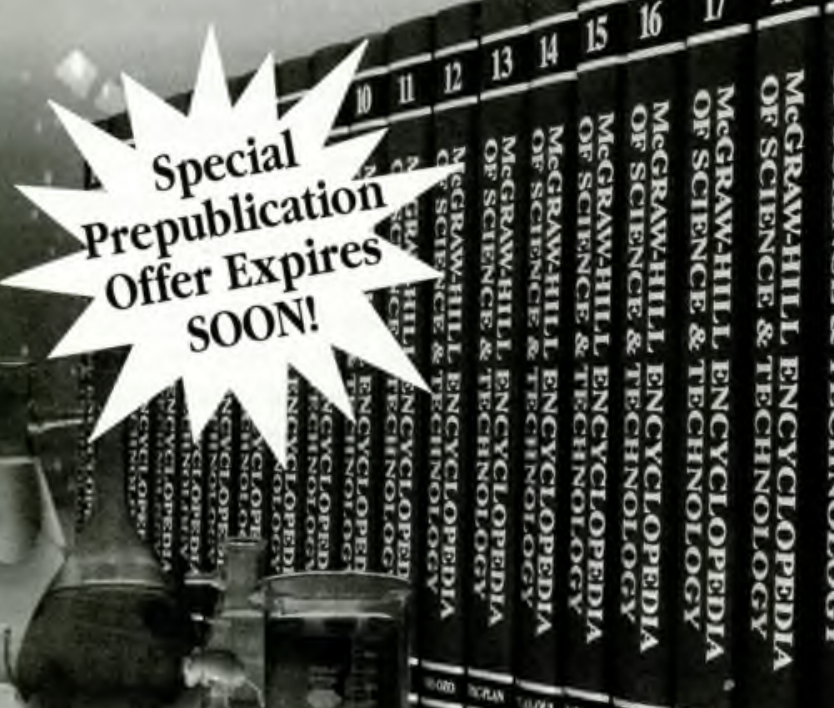
special ublication Prepublicapires SOON!
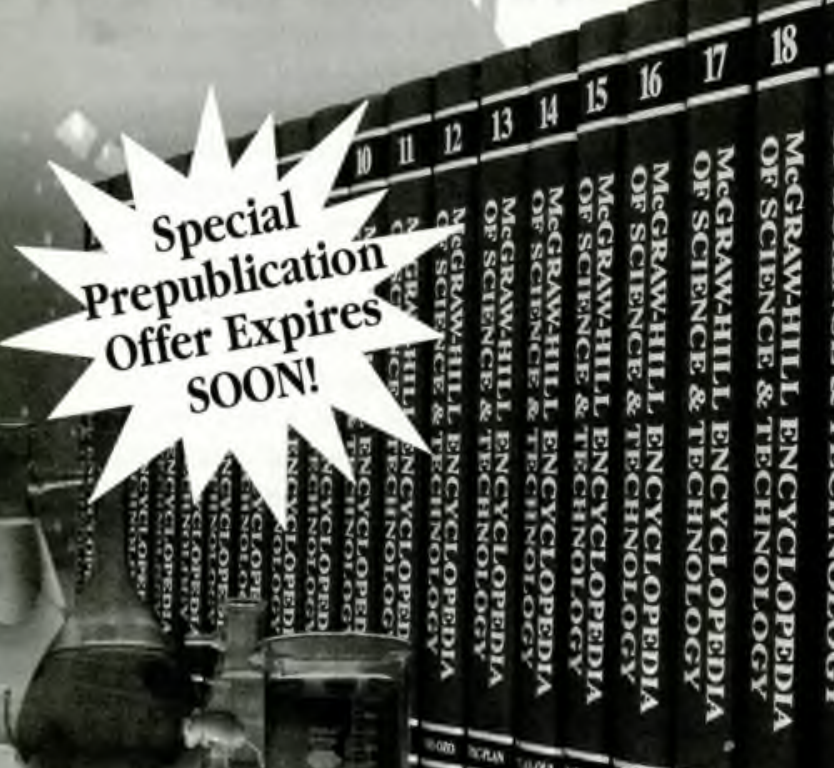

1920

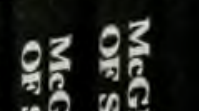

MCGRAWHIILL ENCYCLOPEDL OR

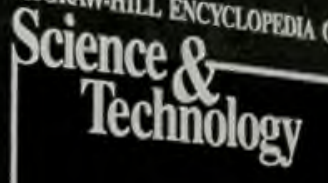

鲜

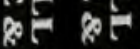

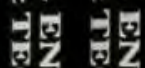

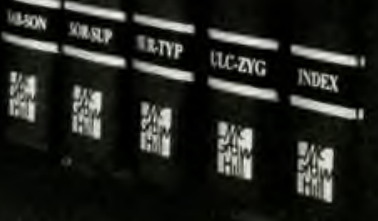
of Science \& Technology, 8th Edition

In every library there should be a first place students, researchers, educators and librarians turn to find information on any scientific or technical subject. A place where the inspiration for starting a research project, the supporting evidence for a paper, or the authoritative answer to an intriguing question can always be found. More than ever, the new Eighth Edition of the McGraw-Hill Encyclopedia of Science \& Technology is that place, with thousands of new and revised articles and illustrations, and completely revised bibliographies. No library should be without the McGraw-Hill Encyclopedia of Science and Tecbnology, Eighth Edition-the first science reference that's a scientific achievement in its own right.

Special Prepublication offerSave Over $\$ 200$ Pre-publication price $\$ 1,750$ tbrougb 5/31/97; si,995 ibereafler. ISBN: 0-07-911504-7 